\title{
BIOFILMES DE Campylobacter spp
}

\section{Ana Beatriz Garcez Buiatte1; Patrícia Lopes Andrade ${ }^{2}$}

${ }^{1}$ Discente do curso de especialização em Controle de Qualidade em Processos Alimentícios, Instituto Federal de Educação, Ciência e Tecnologia do Triângulo Mineiro, Uberlândia, MG, Brasil - anabgbuiatte@hotmail.com

${ }^{2}$ Professora Doutora do Instituto Federal de Educação, Ciência e Tecnologia do Triângulo Mineiro, Uberlândia, MG, Brasil

\section{Recebido em: 04/10/2019 - Aprovado em: 30/11/2019 - Publicado em: 15/12/2019 DOI: 10.18677/EnciBio_2019B8}

\begin{abstract}
RESUMO
O gênero Campylobacter é um dos agentes bacterianos mais comuns nas doenças transmitidas por alimentos em todo o mundo e, geralmente, veiculado pela carne de frangos. A doença é uma causa predominante de gastroenterite aguda no mundo todo. A espécie mais associada à infecção humana é $C$. jejuni, seguido de $C$. coli. Em humanos, a doença é caracterizada por diarreia, dor abdominal, cólicas e febre; pode ocorrer náusea e vômito também, com duração de, em média, uma semana, com riscos de complicações como artrite reativa (síndrome de Reiter), síndrome de Guillain Barré (SGB), e síndrome de Miller Fisher. A maioria dos casos é autolimitante, não requerendo tratamento com antimicrobianos, mas, em pacientes imunodeprimidos, é necessário o tratamento com antimicrobianos. Quando colocadas sob estresse, bactérias do gênero Campylobacter são capazes de se organizar em biofilmes, com objetivo de proteger a comunidade bacteriana das condições ambientais. Essa capacidade está associada a fatores genéticos e ambientais. O controle de biofilmes na indústria pode ser realizado por métodos físicos, químicos e biológicos, isoladamente ou em associações. A dificuldade no controle vem impulsionando estudos em busca de estratégias alternativas.
\end{abstract}

PALAVRAS-CHAVE: biomassa, campilobacteriose, controle.

\section{Campylobacter spp. BIOFILMS}

\begin{abstract}
The genus Campylobacter it is one of the most common bacterial causes of foodborne diseases worldwide and usually results from handling and eating poultry meat. The disease is a predominant cause of acute gastroenteritis worldwide. The species most associated with human infection is $C$. jejuni, followed by $C$. coli. In humans, a disease is characterized by diarrhea, abdominal pain, cramps, and fever; It may also occur on flights also lasting an average of one week, with risks of complications such as reactive arthritis (Reiter's syndrome), Guillain Barré syndrome (GBS) and Miller Fisher syndrome. Most cases are self-limiting, do not require antimicrobial treatment, but in immunosuppressed patients, antimicrobial treatment is required. When placed under stress, bacteria of the genus Campylobacter are able to
\end{abstract}


organize biofilms in order to protect the bacterial community from environmental conditions. This ability is associated with genetic and environmental factors. Control of biofilms in industry can be carried out by medical, chemical and biological methods, either alone or in records. The difficulty in control comes to boost studies in search of alternative alternatives.

KEYWORDS: biomass, campylobacteriosis, control.

\section{INTRODUÇÃO}

Bactérias do gênero Campylobacter spp. estão entre as causas bacterianas mais comuns de doenças transmitidas por alimentos em todo o mundo e geralmente resultado do manuseio e consumo de carne de aves (EFSA, 2017). A doença é uma causa predominante de gastroenterite aguda no mundo todo, com elevada morbidade e custos nos sistemas de saúde de diversos países (CODY, 2017).

Estima-se que Campylobacter cause 166 milhões de casos de doenças por ano (HAVELAAR et al., 2015). Em 2015, segundo a European Food Safety Authority (EFSA, 2017), este patógeno foi o principal agente zoonótico reportado em humanos, com cerca de 246.307 casos notificados. De acordo com o CDC (2017), nos EUA, aproximadamente 1,3 milhão de pessoas são infectadas a cada ano, com uma incidência geral de 14 por 100.000 habitantes. A espécie mais associada à infecção humana é $C$. jejuni, sendo esta a mais patogênica, seguido de $C$. coli (ROWE; MADDEN, 2014; CODY, 2017).

Campylobacter é um habitante comum do trato intestinal de animais de sangue quente, e pode ser transmitida aos humanos pelo consumo de alimentos e água contaminados, incluindo carne crua, produtos cárneos e leite cru (NISAR et al., 2018). Frangos de corte são considerados os principais reservatórios de $C$. jejuni e C. coli (MELO et al., 2017). A contaminação nas propriedades rurais leva a transmissão ao longo da cadeia de produção até o produto final (MELO et al., 2017; GARCÍA-SANCHEZ et al., 2018; NISAR et al., 2018).

Em humanos, a doença é caracterizada por diarreia, dor abdominal, cólicas e febre; pode ocorrer náusea a vômito também. A duração geralmente é de uma semana, e alguns pacientes não apresentam sintomas (WHO, 2017). Podem ocorrer complicações, como artrite reativa (síndrome de Reiter), síndrome de Guillain Barré (SGB), e síndrome de Miller Fisher (TAKAHASHI et al., 2005; OSIMANI et al., 2017; NISAR et al., 2018).

A maioria dos casos é autolimitante, não requerendo tratamento com antimicrobianos (GARCÍA-SÁNCHEZ et al., 2018). Porém, em pacientes imunodeprimidos e jovens, casos de campilobacteriose podem exigir terapia antimicrobiana, e as fluorquinolonas e macrolídeos são as drogas de escolha, a tetraciclina é uma opção alternativa (GARCÍA-SÁNCHEZ et al., 2018). Recentemente houve um aumento da preocupação com o desenvolvimento de resistência a antimicrobianos entre patógenos isolados de alimentos. Tal problema tem sido atribuído ao uso indiscriminado de antimicrobianos na pecuária de forma preventiva, terapêutica, ou como promotor de crescimento (ALFREDSON; KOROLIK, 2007).

Os biofilmes são formas de resistência dos microrganismos a estresse, antibióticos e desinfetantes, o que os tornam importantes para a indústria de alimentos. Biofilmes de Campylobacter são especialmente importantes na indústria avícola, dado que o consumo de carne de frango tem crescido mundialmente (DANIEL et al., 2011; ROILA et al., 2018). 
Assim, objetivou-se com o presente estudo, elaborar uma revisão de literatura abordando a bactéria e seus efeitos no ser humano e ambiente, e seus mecanismos de formação de biofilme, salientando a importância destas estruturas na indústria alimentícia.

\section{Campylobacter spp. E CAMPILOBACTERIOSE}

Bactérias do gênero Campylobacter spp. são bacilos curvos, espiralados, gram negativos, móveis por um flagelo polar, responsável pelo movimento característico em forma de saca-rolha, não formadoras de esporos (LEVIN, 2007; BRASIL, 2011).

Segundo Euzéby (1997), existem mais de 32 espécies e 13 subspécies pertencentes ao gênero Campylobacter spp., e, dentre elas, as espécies termofílicas, que são $C$. jejuni, $C$. coli, $C$. lari e $C$. upsaliensis, importantes agentes veiculados por alimentos e estão associados à gastroenterite em humanos, bem como complicações, crescendo em faixas de temperatura entre $30^{\circ} \mathrm{C}$ e $47^{\circ} \mathrm{C}$, com temperatura ótima de $42^{\circ} \mathrm{C}$ (BRASIL, 2011).

São bactérias microaerófilas, requerendo tensão de oxigênio para multiplicar; o crescimento é inibido quando a concentração de $\mathrm{O}_{2}$ é menor que $3 \%$ e maior que $15 \%$, sendo a concentração ideal de $5 \%$, e requerem cerca de $10 \%$ de $\mathrm{CO}_{2}$ para sua multiplicação. São sensíveis ao sal, sendo esta sensibilidade variável em função da temperatura. São também bastante sensíveis ao $\mathrm{pH}$ ácido, crescendo na faixa de $\mathrm{pH}$ entre 5,5 - 8,0, com valor ótimo próximo do neutro $(6,5-7,5)$ e à desidratação (BRASIL, 2011).

Quando exposta a situações desfavoráveis, a Campylobacter pode retrair seu citoplasma, adquirindo uma forma cocóide, onde ela entra num estado viável não cultivável (VNC), que possibilita que ela mantenha a virulência mesmo exposta a estresse ambiental, podendo retornar a forma espiralada quando as condições ficam favoráveis (KEUM-IL et al., 2007). Esta fase não pode ser cultivada por métodos convencionais de isolamento, o que dificulta o diagnóstico.

A campilobacteriose é uma zoonose de distribuição mundial, e bactérias do gênero Campylobacter spp. estão associadas a animais de sangue quente, comportando como comensais de trato gastrintestinal de várias espécies animais (BRASIL, 2011). As infecções pelo agente são esporádicas, ocorrendo mais no verão e início de outono. Casos de campilobacteriose atingem mais facilmente certos grupos etários, sendo eles crianças jovens ( $<4$ anos de idade), adultos jovens (20-40 anos de idade) e idosos (> 75 anos de idade) (SKARP et al., 2016).

Surtos de campilobacteriose são raros, e estão mais associados com ingestão de leite não pasteurizado, água não tratada e produtos cárneos mal cozidos (BRASIL, 2011). Estudos epidemiológicos relatam que a carne de frango é a principal fonte de transmissão da doença em humanos; pesquisadores estimam que entre $58 \%$ e $78 \%$ das doenças humanas estão relacionados ao consumo de carne de aves contaminada (OH et al., 2015; PRACHANTASENA et al., 2016; CODY, 2017). As duas espécies mais isoladas em casos de infecções alimentares são $C$. jejuni e C. coli (ROWE; MADDEN, 2014; CODY, 2017).

Esses agentes são encontrados nas fezes e, as aves são consideradas portadores assintomáticos (BRASIL, 2011). São microrganismos ubiquitários, com distribuição em ambientes industriais, domésticos e na natureza (LEVIN, 2007). Pesquisas já relataram alta prevalência de Campylobacter em aves, podendo chegar 
a $100 \%$ dos frangos (ELLERBROEK et al.,2010). Em trabalhos realizados com infecções em humanos, o início do desenvolvimento da doença foi relatado a partir de uma dose infectante de 360 UFC a 800 UFC (HARA-KUDO; TAKATORI, 2011; KIRKPATRICK et al., 2013).

Os sinais ocorrem de 2 a 5 dias após a infecção, e o período de incubação varia dependendo do número de bactérias ingeridas (ALLOS, 2015). As pessoas acometidas, em geral, recuperam-se da diarreia em um período de 5 a 10 dias, e, ainda podem apresentar outros sintomas, como febre, dores de cabeça, dores abdominais, náusea, vômitos, perda de peso. O período pré patente é de 24 a 72 horas, e o pico da doença pode durar de 24 a 48 horas, e, nas fezes, podem aparecer sangue e leucócitos (BESSEDE et al., 2014).

A infecção Campylobacter spp. pode ser assintomática e autolimitante, porém, os sintoma mais comuns incluem diarreia, febre e cólicas abdominais (HESSULF et al., 2016; WHO, 2017). O tratamento com antibióticos geralmente não é necessário, e, em muitos casos, só se realiza a terapia de suporte, para reverter os sintomas.

Em menos de $1 \%$ dos casos, pode ser encontrada a bacteremia, e, mais raramente, complicações como artrite, meningite, endocardite, sepse, síndrome de Guillain-Barré, síndrome hemolítico-urêmica (HUS), doença inflamatória intestinal (DII) e distúrbios gastrointestinais funcionais (FGID) (KAAKOUSH et al, 2015; O'BRIEN, 2017). A síndrome de Guillain-Barré é uma doença onde há um estado progressivo simétrico de fraqueza dos membros. Um estudo realizado na Nova Zelândia associou a infecção por $C$. jejuni com a posterior ocorrência de Síndrome de Guillain Barré, e a diminuição de casos foi conquistada através de medidas de higiene na produção avícola; também houve essa associação em outros estudos (KEITHLIN et al., 2014; SIVADON-TARDY et al., 2014). A síndrome de Miller-Fisher, uma variante de SGB, e a síndrome de Reiter, ou artrite reativa, também podem ser desencadeadas pela $C$. jejuni. (TAKAHASHI et al., 2005; OSIMANI et al., 2017; NISAR et al., 2018). Tais complicações podem ser resultado de resposta auto-imune induzida por lipooligossacarídeos do tipo gangliosídeo expresso por C. jejuni (REVEZ et al., 2011). Segundo Hessulf et al. (2016), casos de miocardite e perimocardite são complicações raras que afetam predominantemente homens jovens e saudáveis e, na maioria dos casos, seguem um curso benigno.

Para o diagnóstico da doença, pode ser realizado o cultivo individual, porém vale ressaltar que são microrganismos microaerófilos, com crescimento lento, o que dificulta o cultivo, e causa injúrias ao agente, o que pode modificar a morfologia e o deixar em estádio viável mas não cultivável (VNC) (KEUM-IL et al., 2007). Em estudo de Stetsenko, Efimochkina e Pichugina (2019), os métodos microbiológicos falharam em identificar $40 \%$ das amostras de Campylobacter analisadas, evidenciando assim, a importância da forma viável não cultivável. Mesmo assim, os métodos convencionais de isolamento são empregados em laboratórios de referência.

Em alimentos, os principais métodos são preconizados pela International Organization for Standardization (ISO) 10272-1 e 2 (2006), pelo Bacteriological Analitical Manual Online de Food and Drug Administration (BAM/FDA) e o Food Safety and Inspection Service, United States Departament of Agriculture (BRASIL, 2011).

Podem ser utilizados métodos imunológicos (triagem), bioquímicos (baseiamse no metabolismo) e moleculares (baseado nas características fenotípicas). A 
técnica de reação de polimerase em cadeia (PCR) é uma das técnicas genéticas de maior aplicação em alimentos, sendo segura e vantajosa, pois se baseia em DNA ou RNA bacteriano, porém tem um maior custo (BRASIL, 2011).

Recentemente houve um aumento da preocupação com o desenvolvimento de resistência a antimicrobianos entre patógenos isolados de alimentos. Já foram relatados pela EFSA vários isolados de Campylobacter de humanos resistentes a ciprofloxacina, tetraciclinas, bem como macrolídeos, aminoglicosídeos e betalactâmicos (EFSA, 2015), o que diminui as opções de tratamento e controle da infecção. Segundo Alfredson e Korolik (2007), as espécies de Campylobacter possuem mecanismos genéticos para transformação e conjugação natural, o que indica que se genes de resistência a antibióticos forem adquiridos, esta característica pode ser rapidamente transferida entre linhagens.

\section{BIOFILMES DE Campylobacter jejuni}

Mesmo sendo uma bactéria exigente para crescimento, já foi comprovada a capacidade da Campylobacter de superar procedimentos de limpeza e desinfecção, mantendo a persistência em longos períodos (PEYRAT et al., 2008; GARCíASÁNCHEZ et al., 2017). Biofilmes são massas formadas a partir de adesão de células bacterianas a uma superfície e a união das células forma uma comunidade bacteriana envolvida por matriz polimérica, a qual protege o biofilme, dificultando a penetração de agentes biocidas, e concentrando nutrientes (AZEVEDO; CERCA, 2012).

A bactéria transita entre vida livre e forma séssil, ligada a superfície biótica ou abiótica, cercada por matriz viscosa (MELO et al., 2017). A camada de exopolissacarídeo (EPS) protege a população bacteriana das condições ambientais, além do que, as bactérias apresentam taxas mais lentas de crescimento e metabolismo (REUTER et al., 2010; BORGES et al., 2016). A estrutura do biofilme é ligada a uma matriz polimétrica extracelular (EPM), que se trata de uma mistura de polissacarídeos, proteínas e ácidos nucléicos, que dão estabilidade, adesão, absorção, e manutenção de nutrientes e resistências a agentes estressores (LIMOLI et al., 2015; FLEMMING et al., 2016).

Os abatedouros de frangos geram resíduos ricos em proteínas e lipídeos, que podem se depositar nas superfícies, favorecendo a formação de biofilmes de Campylobacter. Nas indústrias, as bactérias podem formar biofilmes em alimentos e na área de processamento, sobre diversas superfícies, tais como vidro, plástico e aço (REUTER et al., 2010; BRONOWSKI et al., 2014; BROWN et al., 2015; BRONNEC et al., 2016).

A formação de biofilme pode ser mais eficiente com a presença do "chicken juice" (suco de frango), podendo levar a biofilmes fortemente aderentes, gerando uma forma de persistência em abatedouros (REUTER et al., 2010; BROWN et al., 2015; MELO et al., 2017). As partículas nutritivas no "chiken juice" podem formar uma fina camada acima das superfícies abióticas que facilitam essa adesão bacteriana (LI et al., 2017).

Estudo recente demonstrou que o uso de antibióticos no tratamento de doenças pode induzir a formação de biofilme por algumas cepas de $C$. jejuni, sendo uma preocupação para a saúde pública (TEH et al., 2019b). Malik e colaboradores (2017) verificaram que a população de $C$. jejuni em biofilmes é 32 vezes mais resistente a gentamicina do que nas formas planctônicas. 
Os biofilmes são formados por um ciclo de cinco fases, a saber: Fase livre, Fixação à superfície, Micro-colônia, Macro-colônia e Dispersão (ROSSI et al., 2016). No primeiro estágio, o agente fixa-se de forma reversível a superfície, e essa fixação é facilitada pela motilidade flagelar; trata-se de uma fase onde é possível a fácil remoção do agente por procedimento de limpeza (ROSSI et al., 2016).

O segundo estágio já apresenta uma fixação irreversível, com aumento da intensidade da ligação, realizada por produção de exopolímeros e adesinas; nessa fase, para remoção é necessário uso de força mecânica ou tratamento químico (VESTERLUND et al., 2005). No terceiro estágio há a formação de microcolônias, aproximadamente em quatro horas após a etapa de fixação, e assim, as células ficam imóveis e o mecanismo de quorum-sensing é ativado; assim, nessa fase os fatores extrínsecos também atuam na capacidade de adesão, como superfície de fixação, condições ambientais e nutrientes (MOE et al., 2010).

No quarto estágio, há formação de macro colônias, com uma difusão de exopolímeros mais lenta que o metabolismo celular e os gradientes químicos resultantes criam micro nichos, que evidenciam em seu interior, zonas de morte bacteriana, permitindo a formação de cavidades, onde as formas planctônicas se tornam móveis (CAPPITELLI et al., 2014), o que dura até três dias (SUNG; KHAN, 2015). No quinto estágio há a dispersão das formas planctônicas para formação de mais biofilmes, processo passivo independente da concentração de oxigênio (CAPPITELLI et al., 2014).

C. jejuni foi relatado como fraco iniciador de biofilmes (TEH et al., 2019a). Biofilmes mistos, muito encontrados em indústrias de alimentos, representam maior risco, pois as bactérias podem se proteger durante a aplicação de agentes químicos. O comensalismo entre $C$. jejuni e $P$. aeruginosa promove fixação aprimorada de $C$. jejuni a biofilmes, e um aumento na tolerância de concentrações de oxigênio para $C$. jejuni (CULOTTI; PACKMAN, 2015; TEH et al., 2019a). Curiosamente, em trabalho de Melo e colaboradores (2017), biofilme misto com $P$. aeruginosa na presença de "chicken juice" teve uma produção de biomassa menor, mostrando que algum fator presente no suco poderia inibir a transição para a forma séssil nessa espécie.

\section{Fatores extrínsecos e intrínsecos na formação de biofilme}

Já foram caracterizados vários genes capazes de contribuir para a formação de biofilmes em $C$. jejuni, incluindo os que codificam para motilidade ( $f l a A$, flaB, flaC, flaG, fliA, fliS, flgA e flhA), resposta ao estresse (spoT, csrA, ahpC, cosR e cprS), modificações na superfície bacteriana (peb4, waaF, pgp1) e detecção de quorum sensing (IuxS) (GARCÍA-SANCHEZ et al., 2019; WAGLE et al., 2019). O CosR possivelmente é uma proteína responsável pela formação de biofilme, envolvido na expressão da bomba de efluxo CmeABC (TURONOVA et al., 2015). Outros genes envolvidos são: cadF (adesão celular), dnaJ (termotolerancia), cbr (resistência ao choque osmótico), htrA (crescimento sob estresse), e sodB (tolerância oxidativa) (REUTER et al., 2010. PLUMMER, 2012; OH; JEON, 2014).

Em um primeiro momento, a formação de biofilme é mediada por flagelos, para a adesão celular. Embora os genes flagelares flaA e flaB tenham sido necessários para a formação de biofilme, a ausência dessas características não impede a aquisição de forma séssil, mas provoca formação de biofilmes mais fracos; a expressão desses genes tem vantagem para fixação, estruturação do biofilme, orientação a biofilme pré-existente (SVENSSON et al., 2014; KIM et al., 2015). O 
gene cadF codifica as proteínas de ligação fibronectina CadF (PLUMMER, 2012). A ausência destes genes, somado a ausência dos genes envolvidos no mecanismo de quimiotaxia, como che $A$, cheY e cet $B$ reduzem o mecanismo de auto aglutinação (TURONOVA et al., 2015).

O quorum sensing indica a capacidade de ligação entre células, desenvolvimento e desapego do biofilme (PLUMMER, 2012). Trata-se de um mecanismo de sinalização dependente da população bacteriana, que envolve síntese e detecção de autoindutores (Al) (BASSLER, 1999), onde, ao detectar esses Als, as comunidades iniciam e regulam a resposta ao sinal. Campylobacter produz Al-1 (autoindutor acil-hemoserina), o qual, a partir de determinada concentração intracelular, se liga a um ativador de transcrição celular (luxS) que codifica luciferase, uma enzima metabólica que atua na reciclagem de SAM (S-adenosilmetionina), essencial no desempenho de reações biossintéticas (PARVEEN; CORNELL, 2011). O gene luxS sintetiza Al-2 (RAJAN et al., 2005), cujas concentrações se elevam quando a população bacteriana cresce; tal molécula reconhece populações mistas em biofilme. A produção de Al-2 depende de nutrientes encontrados em fontes de alimentos, como leite e o "chicken juice" (PLUMMER, 2012).

O processo de tolerância a altas temperaturas também é conhecido como resposta adaptativa específica, resposta adaptativa múltipla ou proteção cruzada (ISOHANNI et al., 2013). A bactéria responde a situação de estresse térmico através da síntese de um grupo de proteínas conservadas, que têm a síntese aumentada com a variação de temperatura (BEALES, 2006). O gene dnaJ, quando expresso, permite que a cepa codifique uma proteína que permite o crescimento a temperaturas maiores de $40^{\circ} \mathrm{C}$ (KONKEL et al., 1998).

Para sobreviver a situações de estresse por baixas temperaturas, a $C$. jejuni pode expressar proteínas SOD (sueróxido desmutase). Foram descritos três tipos de enzimas SODs: sodB (cofatores com ferro), sodA (manganês) e sodC (cobre e zinco); tais enzimas atuam quebrando moléculas de superóxido, sendo um mecanismo de defesa contra estresse oxidativo (STINTZI; WHITWORTH, 2003; KIM et al., 2015).

O microambiente do biofilme apresenta abundância de DNA, em consequência de organismos lisados, mortos ou mesmo pela secreção das bactérias (NIELSEN et al., 2007).O DNA extracelular (eDNA) é um componente abundante de vários biofilmes (INDIKOVA et al., 2015), e tem sua importância na fixação, crescimento e transferência horizontal de genes, assim como fonte de nutrição, e pode ser usado como suprimento de nutrientes ou até mesmo se tornar parte do genoma de outras bactérias (FENG et al., 2017). O eDNA já foi detectado no sobrenadante ao redor da biomassa de biofilme de $C$. jejuni (BROWN et al., 2015). Em estudos de Feng e colaboradores (2017), a presença de eDNA durante a formação do biofilme foi constatada, inclusive em quantidades maiores que outros componentes do biofilme, como proteínas, lipídeos e polissacarídeos.

Alguns fatores ambientais determinam a formação de biofilme. Dentre eles, pode-se citar $\mathrm{pH}$, temperatura, tipo de material, presença de compostos, pressão osmótica, concentração de oxigênio, disponibilidade de nutrientes e presença de agentes microbianos (GUINEY, 1997).

A menor quantidade de nutrientes intensifica o modo de crescimento séssil, pelo aumento da produção de LPS na matriz (REESER et al., 2007). A superfície interfere na adesão de microrganismos, e as bactérias se aderem mais facilmente à superfícies hidrofóbicas (DONLAN; COSTERTON, 2002). O estresse osmótico pode 
inibir a formação de biofilme, porém pode induzir a transição para morfologia cocóide (REESER et al., 2007).

A tensão de oxigênio tem efeito na formação de biofilme. A presença de oxigênio parece favorecer a formação inicial de biofilmes; em trabalho de Stetsenko e colaboradores (2019), biofilmes de $C$. jejuni formaram biofilmes mais fortes em condições aeróbicas a $25 \stackrel{\circ}{ } \mathrm{C}$.

\section{Controle de biofilmes}

A prevenção e eliminação de biofilmes são realizadas através de métodos físicos, químicos e biológicos, e a combinação dos três métodos se mostrou mais eficiente (MALAEB et al., 2013). Deve-se levar em consideração os materiais e a disposição dos equipamentos na indústria, pois são importantes para prevenir a formação de biofilmes, devendo evitar problemas por partes inacessíveis ou vulneráveis para o acúmulo de matéria orgânica e consequente adesão de bactérias (CHMIELEWSKI; FRANK, 2006).

A limpeza mecânica é uma das principais medidas de eliminação e controle de biofilmes através do atrito, com a finalidade de destruir a matriz e expor as camadas mais profundas, acessando as bactérias (MAUKONEN et al., 2003). A limpeza mecânica deve ser realizada sem o uso de equipamentos abrasivos, que possam causar danos à superfície causando corrosão, pois, estes facilitam também a formação de biofilme. Altas temperaturas podem ser usadas para diminuir a necessidade de uso de força.

A lavagem diária seguida por desinfetantes aprovados por órgão competente é recomendada. Os produtos mais usados são tensoativos ou alcalinos, com a finalidade de dissolver resíduos alimentares, emulsionar gorduras e desnaturar proteínas (MAUKONEN et al., 2003).

A desinfecção, método usado para reduzir a carga microbiana da superfície depois da limpeza, deve ser realizada com desinfetantes que tenham a eficácia comprovada, além de seguros aos manipuladores, e devem ser retirados da superfície de forma fácil (SREY et al., 2013). Os mais usados são os ácidos, biocidas a base de aldeídos, produtos cáusticos, cloro, peróxido de hidrogênio, iodo, isotiazolinonas, ozônio, ácido peracético, fenóis, biguanidas e surfactantes (BREMER et al., 2006; SIMÕES et al., 2006). O uso de compostos químicos tem ação limitada, pois não destroem as estruturas da matriz, podendo ocorrer o ressurgimento do biofilme (OHSUMI et al., 2015). Assim, são necessários esforços especiais para a remoção completa de biofilmes altamente aderentes adaptados aos biocidas de $C$. jejuni (TECHARUVICHIT et al., 2016).

Outras abordagens envolvem uso de enzimas degradadoras (destruir a matriz), bacteriófagos, quelantes de ferro (bloqueio da adesão bacteriana) e nanopartículas (destruir biomassa) (SRINGAN et al., 2011; MATYAR et al., 2014; BROWN et al., 2015; KIM et al., 2017; OH et al., 2018).

O uso de enzimas degradantes foi estudado para biofilmes de $C$. jejuni, e a eficácia pode ser diminuída quanto há produção de EPS e atividade proteolítica de exoenzimas produzidas pelo biofilme maduro (BROWN et al., 2015; KIM et al., 2017). Quanto ao uso de bacteriófagos, há uma limitação da aplicação pela possibilidade de resistência (SIRINGAN et al., 2011).

Em trabalho de Melo e colaboradores (2017), o uso de clorexidina 1\%, hipoclorito de sódio $1 \%$ e ácido peracético 0,8\% apresentaram maior eficiência no 
controle de biofilmes de $C$. jejuni quando comparados a nanopartículas de $\mathrm{ZnO}$. Por outro lado, tolerância aos desinfetantes, verificada em trabalhos, sugere que o uso de maneira inadequada destes na indústria, como a exposição a subdoses, leva a adaptação dessas bactérias (TECHARUVICHIT et al., 2016; MELO et al., 2017).

Fitoquímicos também têm sido estudados, e, em estudos de Wagle e colaboradores (2019), para verificar a eficiência antibiofilme de trans-cinnamaldeído, um aldeído extraído da casca de canela, e carvacrol, componentes ativos do óleo de cravo-da-índia concluiram que todos os compostos reduziram a formação de biofilmes e os biofilmes maduros. Roila e colaboradores (2019) estudaram o potencial de extrato polifenólico de águas residuais do moinho de azeitonas como fonte alternativa para controle de biofilme de $C$. jejuni e $C$. coli, obtendo bons resultados, onde o composto foi capaz de inibir a formação de biofilmes.

Melo e colaboradores (2017) obtiveram uma redução da biomassa de biofilme de $C$. jejuni usando metaperiodato de sódio e proteinase $\mathrm{K}$, dois compostos que digerem a matriz. Segundo os autores, estes compostos podem melhorar a penetração de agentes antimicrobianos na matriz, abrindo porta para desenvolvimento de proteolíticos semelhantes para uso industrial, associados a desinfetantes. Assim, sugere-se a associação de planos de higiene a agentes diferentes, respeitando período entre limpezas, além do uso de estratégias, como a rotação periódica dos biocidas (MELO et al., 2017).

\section{CONSIDERAÇÕES FINAIS}

Campylobacter é um patógeno zoonótico importante no cenário mundial. A bactéria pode causar no ser humano, desde sinais digestivos até síndromes mais complexas, como a síndrome de Guillain Barré.

Os microrganismos, mesmo com a dificuldade de cultivo em laboratório, conseguem sobreviver em produtos animais, principalmente na carne de frango, adotando uma série de medidas para tolerância em ambientes adversos, como conversão para a forma VNC e a formação de biofilmes. A formação de biofilme é um grande desafio para o fornecimento de produtos que não representem riscos à saúde do consumidor, principalmente para as indústrias alimentícias. Existem, no momento, técnicas mecânicas, químicas e biológicas que visam o controle da formação de biofilmes de Campylobacter. Ainda assim, diante da dificuldade de controle da formação, de seus mecanismos de resistência, muitos estudos estão em desenvolvimento para pesquisa de métodos alternativos de controle.

\section{REFERÊNCIAS}

ALFREDSON, D. A.; KOROLIK, V. Antibiotic resistance and resistance mechanisms in Campylobacter jejuni and Campylobacter coli. Fems Microbiology Letters, v. 277, n. 2, p.123-132, 2007. DOI: https://doi.org/10.1111/j.1574-6968.2007.00935.x

\section{ALLOS, B. M. Microbiology, pathogenesis, and epidemiology of Campylobacter infection. $2015 . \quad$ Uptodate. Disponível em:} https://www.uptodate.com/contents/microbiology-pathogenesis-and-epidemiology-ofcampylobacter-infection . Acesso em: 22 set. 2019.

AZEVEDO, N. F.; CERCA, N. Bioflms in: health, environment, industry. Porto: Publindústria, 2012. 396 p. 
BASSLER, B. L. How bacteria talk to each other: regulation of gene expression by quorum sensing. Current Opinion in Microbiology, v. 2, n. 6, p. 582-587, 1999. URL: https://www.ncbi.nlm.nih.gov/pubmed/10607620. Acesso em: set. 2019.

BEALES, N. Adaptation of microorganims to cold temperatures, weak acid preservatives, low $\mathrm{pH}$, and osmotic stress: a review. Comprehensive Reviews in Food Science and Food Safety, v. 3, n. 1, p. 1-20, 2006. DOI: https://doi.org/10.1111/j.1541-4337.2004.tb00057.x

BESSEDE, E.; LEHOURS, P.; LABADI, L.; BAKIRI, S.; MÉGRAUD, F. Comparison of characteristics of patients infected by Campylobacter jejuni, Campylobacter coli and Campylobacter fetus. Journal of Clinical Microbiology, v. 52, n. 1, p. 328-330, 2014. DOI: https://doi.org/10.1128/JCM.03029-13

BORGES, A.; ABREU, A.; DIAS, C.; SAAVEDRA, M.; BORGES, F. et al. New perspectives on the use of phytochemicals as an emergent strategy to control bacterial infections including biofilms. Molecules, v. 21, n.7, p. 877, 2016. DOI: https://doi.org/10.3390/molecules21070877

BRASIL. Ministério da Saúde. Secretaria de Vigilância em Saúde. Manual técnico de diagnóstico laboratorial de Campylobacter / Ministério da Saúde. Secretaria de Vigilância em Saúde, Fundação Oswaldo Cruz, Laboratório de Referência Nacional de Enteroinfecções Bacterianas, Instituto Adolfo Lutz. - Brasília : Ministério da Saúde, 2011.

BREMER, P. J.; FILLERY, S.; MCQUILLAN, A. J. Laboratory scale clean-in-place (CIP) studies on the effectiveness of different caustic and acid wash steps on the removal of dairy biofilms. International Journal of Food Microbiology, v. 106, n. 3, p. 254-262, 2006. DOI: https://doi.org/10.1016/j.ijfoodmicro.2005.07.004

BRONNEC, V.; TURNOVÁ, H.; BOUJU, A.; CRUVEILLER, S.; RODRIGUES et al. Adhesion, biofilm formation, and genomic features of Campylobacter jejuni $\mathrm{Bf}$, an atypical strain able to grow under aerobic conditions. Frontiers in Microbiology, v.7, 2016. DOI: https://doi.org/10.3389/fmicb.2016.01002

BRONOWSKI, C.; JAMES, C. E.; WINSTANLEY, C. Role of environmental survival in transmission of Campylobacter jejuni. FEMS Microbiology Letters, v. 356, n. 1, p. 8-19, 2014. DOI: https://doi.org/10.1111/1574-6968.12488

BROWN, H. L.; REUTER, M.; HANMAN, K.; BETTS, R. P.; van VLIET, A. H. Prevention of biofilm formation and removal of existing biofilms by extracellular DNases of Campylobacter jejuni. PLoS One, v.10, n.3, 2015. DOI: https://doi.org/10.1371/journal.pone.0121680

CAPPITELLI, F.; POLO, A.; VILLA, F. Biofilm formation in food processing environments is still poorly understood and controlled. Food Engineering Reviews, v. 6, n. 1, p. 29-42, 2014. DOI: https://doi.org/10.1007/s12393-014-9077-8 
CDC (Centers for Disease Control and Prevention). Campylobacter (Campylobacteriosis). $2017 . \quad$ Disponível em: https://www.cdc.gov/campylobacter/index.html. Acesso em: 18 jul. 2019.

CHMIELEWSKI, R. A. N.; FRANK, J. F. A predictive model for heat inactivation of Listeria monocytogenes biofilm on rubber. LWT - Food Science and Technology, v. 39, n. 1, p. 11-19, 2006. DOI: https://doi.org/10.1016/j.Iwt.2004.10.006

CODY, A. J. Core genome multilocus sequence typing scheme fot stable, comparative analyses of Campylobacter jejuni and C. coli human disease isolates. Journal of clinical microbiology, v. 55, n. 7, 2017. DOI: https://doi.org/10.1128/JCM.00080-17

CULOTTI, A.; PACKMAN, A. I. Pseudomonas aeruginosa facilitates Campylobacter jejuni growth in biofilms under oxic flow conditions. FEMS Microbiology Ecology, v. 91, n. 12, p. 136, 2015.

DANIEL, C. R.; CROSS, A. J., KOEBNICK, C.; SINHA, R. (2011). Trends in meat consumption in the USA. Public Health Nutrition, v.14, n.4, p.575-583, 2011. DOI: http://dx.doi.org/10.1017/S1368980010002077

DONLAN, R. M.; COSTERTON, J. M. Biofilms: Survival mechanisms of clinically relevant microorganisms. Clinical Microbiology Review, v. 15, n. 2, p. 167-193, 2002. DOI: https://doi.org/10.1128/cmr.15.2.167-193.2002

EFSA (European Food Safety Authority) and ECDC (EuropeanCentre for Disease Prevention and Control).EU SummaryReport on antimicrobial resistance in zoonotic and indicatorbacteria from humans, animals and food in 2013.EFSA Journal,v.13, n.2, 178 p., 2015.Disponível em: https://ecdc.europa.eu/sites/portal/files/media/en/publications/Publications/antimicrob ial-resistance-zoonotic-bacteria-humans-animals-food-EU-summary-report-2013.pdf. Acessoem: 01 set. 2019.

EFSA (European Food Safety Authority). The European Union summary report on antimicrobial resistance in zoonotic and indicator bacteria from humans, animals and food in 2015. EFSA Journal, v. 15, n. 2, 212 p, 2017. Disponível em: https://www.efsa.europa.eu/en/efsajournal/pub/4694.Acesso em: 20 set. 2019.

ELLERBROEK, L. I.; LIENAU, J. A.; KLEIN, G. Campylobacter spp. In Broiler Flocks at Farm Level and the Potential for Cross-Contamination During Slaughter. Zoonoses and Public Health, v. 57, n. 7-8, p. 81-88, 2010. DOI: https://doi.org/10.1111/j.1863-2378.2009.01267.x

EUZÉBY, J. P. List of bacterial names with standing in nomenclature: a folder available on the internet. International Journal System Bacteriology. V.47, n.2, 1997.DOI: https://doi.org/10.1099/00207713-47-2-590

FENG, J.; MA, L.; NIE, J.; KONKEL, M. E.; LU, X. Environmental Stress-Induced Bacterial Lysis and Extracellular DNA Release Contribute to Campylobacter jejuni 
Biofilm Formation. Applied and Environmental Microbiology, v.84, n.5, p. 563-575, 2017. DOI: https://doi.org/10.1128/AEM.02068-17

FLEMMING, H. C.; WINGENDER, J.; SZEWZYK, U.; STEINBERG, P.; RICE, S. A. et al. Biofilms: an emergent form of bacterial life. Nature Reviews Microbiology, v. 14, p. 563-575, 2016. DOI: https://doi.org/10.1038/nrmicro.2016.94

GARCÍA-SÁNCHEZ, L.; MELERO, B.; JAIME, I.; HÄNNINEN, M.L.; ROSSI, M. et al. Campylobacter jejuni survival in a poultry processing plant environment. Food Microbioly, v.65, p. 185-192, 2017. DOI: https://doi.org/10.1016/j.fm.2017.02.009.

GARCÍA-SÁNCHEZ, L.; MELERO, B.; DIEZ, A. M.; JAIME, I.; ROVIRA, J. Characterization of Campylobacter species in Spanish retail from different fresh chicken products and their antimicrobial resistance. Food Microbiology, v. 76, p.457-465, 2018. DOI: https://doi.org/10.1016/j.fm.2018.07.004

GARCÍA-SÁNCHEZ, L.; MELERO, B.; JAIME, I.; ROSSI, M.; ORTEGA, I. et al. Biofilm formation, virulence and antimicrobial resistance of different Campylobacter jejuni isolates from a poultry slaughterhouse. Food Microbiology, v. 83, p. 193-199, 2019. DOI: https://doi.org/10.1016/j.fm.2019.05.016

GUINEY, D. G. Regulation of bacterial virulence gene expression by the host environment. Journal of Clinical Investigation, v. 99, p. 565-569, 1997. DOI: http://doi.org/10.1172/JCl119196

HARA-KUDO, Y.; TAKATORI, K. Contamination level and ingestion dose of foodborne pathogens associated with infections. Epidemiology and Infection, v. 139, n. 10, p. 1505-1510, 2011. DOI: https://doi.org/10.1017/S095026881000292X

HAVELAAR, A. H.; KIRK, M. D.; TORGERSON, P. R.;GIBB, H. J.; LAKE, R. J. et al. World Health Organization Global Estimates and Regional Comparisons of the Burden of Foodborne Disease in 2010. Plos Medicine, v. 12, n. 12, p.1-23, 2015. DOI: https://doi.org/10.1371/journal.pmed.1001923

HESSULF, F.; LJUNGBERG, J.; JOHANSSON, P. A.; LINDGREEN, M.; ENGDAHL, J. Campylobacter jejuni associated perimyocarditis: two case reports and review of the literatura. BMC Infectious Diseases, v. 16, 2016. DOI: https://doi.org/10.1186/s12879-016-1635-7

INDIKOVA, I.; HUMPHREY, T. J.; HILBERT, F. Survival with a helping hand: Campylobacter and microbiota. Frontiers in Microbiology, v. 6, 2015. DOI: https://doi.org/10.3389/fmicb.2015.01266.

ISOHANNI, P.; HUEHN, S.; AHO, T.; ALTER, T.; LYHS, U. Heat stress adaptation induces cross-protection against lethal acid stress conditions in Arcobacter butzleri but not in Campylobacter jejuni. Food Microbiology, v. 34, n. 2, p. 431-435, 2013. DOI: https://doi.org/10.1016/j.fm.2013.02.001 
KAAKOUSH N. O.; CASTAÑO-RODRIGUEZ, N.; MITCHELL, H.; MAN, S. M. Global epidemiology of Campylobacter infection. Clinical Microbiololy Revision., v.28, n.3, p.687-720, 2015. DOI: https://doi.org/10.1128/CMR.00006-15

KEITHLIN, J.; SARGEANT, J.; THOMAS, M. K.; FAZIL, A. Systematic review and meta-analysis of the proportion of Campylobacter cases that develop chronic sequelae. BMC Public Health, v. 14, n. 1, p. 1203, 2014. DOI: https://doi.org/10.1186/1471-2458-14-1203

KIM, J.; PARK, C.; KIM, Y. Role of flgA for flagellar biosynthesis and biofilm formation of Campylobacter jejuni NCTC11168. Journal Microbiology Biotechnology, v. 25, p. 1871-1879, 2015. DOI: https://doi.org/10.4014/jmb.1504.04080

KIM, S. H.; PARK, C.; LEE, E. J.; BANG, W. S.; KIM, Y. J. et al. Biofilm formation of Campylobacter strains isolated from raw chickens and its reduction with DNase I treatment. Food Control, v. 71, p. 94-100, 2017. DOI: https://doi.org/10.1016/j.foodcont.2016.06.038

KIRKPATRICK, B. D.; LYON, C. E.; PORTER, C. K.; MAUE, A. C.; GUERRY, P. et al. Lack of homologous protection against Campylobacter jejuni CG8421 in a human challenge model. Clinical Infectious Diseases, v. 57, n. 8, p. 1106-1113, 2013. DOI: https://doi.org/10.1093/cid/cit454

KONKEL, M. E.. KIM, B. J; KLENA, J. D.; YOUNG, C. R.; ZIPRIN, R. Characterization of the thermal stress response of Campylobacter jejuni. Infection and Immunity, v. 66, n. 8, p. 3666-3672, 1998. URL: https://www.ncbi.nlm.nih.gov/pmc/articles/PMC108400/. Acesso em: 25 set. 2019.

LEVIN, R. E. Campylobacter jejuni: A review of its characteristics,pathogenicity, ecology, distribution, subspecies characterization andmolecular methods of detection. Food Biotechnology, v. 21, p.271- 347, 2007. DOI: https://doi.org/10.1080/08905430701536565

LI, J.; FENG, J.; MA, L.; de La FUENTE, N.; GÖLZ, G. et al. Effects of meat juice on biofilm formation of Campylobacter and Salmonella. International Journal of Food $\begin{array}{llll}\text { Microbiology, } & \text { v. } 253, & n .2017 . & \text { DOI: }\end{array}$ https://linkinghub.elsevier.com/retrieve/pii/S0168160517301721

LIMOLI D.; JONES C.; WOZNIAK D. Bacterial extracellular polysaccharides in biofilm formation and function. Microbiology Spectre, v.3, n.3, 2015. DOI: https://doi.org/10.1128/microbiolspec.MB-0011-2014

MALAEB, L. LE-CLECH, P.; VROUWENVELDER, J. S.; AYOUB, G.M. A.; SAIKALY, P. E. Do biological-based strategies hold promise to biofouling control in MBRs? Water Research, v. 47, n. 15, p. 5447-5463, 2013. DOI: https://doi.org/10.1016/j.watres.2013.06.033.

MALIK, H.; RAJAGUNALAN, S.; KUMAR, M. S.; KATARIA, J. L.; ANJAY, P., SACHAN, S.; et al. Assessment of antibiotics effect on planktonic and biofilm forms 
of Campylobacter Isolates. Israel Journal of Veterinarian Medicine, v. 72, n.4, 2017. URL: http://www.ijvm.org.il/sites/default/files/malik.pdf. Acesso em 20 set. 2019.

MATYAR, F. GÜLNAZ, O.; GUZELDAG, G.; MERCIMEK, H. A.; AKTURK, S. et al. Antibiotic and heavy metal resistance in Gram-negative bacteria isolated from the Seyhan Dam Lake and Seyhan River in Turkey. Annals of Microbiology, v. 64, n. 3, p. 1033-1040, 2014. DOI: https://doi.org/10.1007/s13213-013-0740-8

MAUKONEN, J.; MÄTTÖ, J.; WIRTANEN, G.; RAASKA, L.; MATTILA-SANDHOLM, $T$. et al. Methodologies for the characterization of microbes in industrial environments: a review. Journal of Industrial Microbiology and Biotechnology, v. 30, p. 327-356, 2003. DOI: https://doi.org/10.1007/s10295-003-0056-y

MELO, R. T.; MENDONÇA, E. P.; MONTEIRO, G. P.; SIQUEIRA, M. C.; PEREIRA, C. B.; et al. Intrinsec and Extrinsic Aspects on Campylobacter jejuni Biofilms. Frontiers in Microbiology, v.8, 2017. DOI: http://doi.org/10.3389/fmicb.2017.01332

MOE, K. K.; MIMURA, J.; OHNISHI, T.; WAKE, T.; YAMAZAKI, W. et al. The mode of biofilm formation on smooth surfaces by Campylobacter jejuni. Journal of Veterinary Medical Science, v. 72, n. 4, p. 411-416, 2010. DOI: https://doi.org/10.1292/jvms.09-0339

NIELSEN, K. M.; JOHNSEN, P. J.; BENSASSON, D.; DAFFONCHIO, D. Release and persistence of 653 extracellular DNA in the environment. Environmental Biosafety Research, v.6, p. 37-53, 2007. DOI: https://doi.org/10.1051/ebr:2007031

NISAR, M; AHMAD, M. U. D.; MISHTAG, M. H.; SHEHZAD, W.; HUSSAIN, A. et al. Occurrence of Campylobacter in retail meat in Lahore, Pakistan. Acta Tropica, v.185, p.42-45, set. 2018. DOI: https://doi.org/10.1016/j.actatropica.2018.04.030

O'BRIEN, S. J. The consequences of Campylobacter infection. Current Opinion, v.33, n.1, 2017. DOI: https://doi.org/10.1097/MOG.0000000000000329

OH, E.; MCMULLEN, L.; JEON, B. High prevalence of hyper-aerotolerant Campylobacter jejuni in retail poultry with potential implication in human infection. Frontiers in Microbiology, v. 6, p. 1263, 2015. DOI: https://doi.org/10.3389/fmicb.2015.01263

$\mathrm{OH}$, E.; JEON, B. Role of alkyl hydroperoxide reductase (AhpC) in the biofilm formation of Campylobacter jejuni. PLoS ONE, v.9, $2014 . \quad$ DOI: http://doi.org/10.1371/journal.pone.0087312

OH, E.; ANDREWS, K. J.; JEON, B. Enhanced biofilm formation by ferrous and ferric iron througgh oxidative stress in Campylobacter jejuni. Frontiers in Microbiology, v. 9, jun. 2018. DOI: https://doi.org/10.3389/fmicb.2018.01204

OHSUMI, T.; TAKENAKA, S.; WAKAMATSU, R.; SAKAUE, Y.; NARISAWA, N.; et al. Residual structure of Streptococcus mutans biofilm following complete disinfection 
favors secondary bacterial adhesion and biofilm re-development. PLoS ONE, v.10, n.1, 2015. DOI: https://doi.org/10.1371/journal.pone.0116647

OSIMANI, A. AQUILANTI, L.; PASQUINI, M.; CLEMENTI, F. Prevalence and risk factors for thermotolerant species of Campylobacter in poultry meat at retail in Europe. Poultry Science, v.96, n.9, p.3382-3391, 2017. DOI: https://doi.org/10.3382/ps/pex143

PARVEEN, N.; CORNELL, K. A. Methylthioadenosine/S-adenosylhomocysteine nucleosidase, a critical enzyme for bacterial metabolism. Molecular Microbiology, v. 79, n. 1, p. 7-20, 2011. DOI: https://doi.org/10.1111/j.1365-2958.2010.07455.x

PEYRAT, M.B.; SOUMET, C.; MARIS, P.; SANDERS, P. Recovery of Campylobacter jejuni from surfaces of poultry slaughterhouses after cleaning and disinfection procedures: analysis of a potential source of carcass contamination. International Journal of Food Microbiology, v.124, p.188-194, 2008. DOI: https://doi.org/10.1016/j.ijfoodmicro.2008.03.030

PLUMMER, P. J. LuxS and quorum-sensing in Campylobacter. Frontiers in Cellular and Infection Microbiology, v. 2, n. 22, 2012. DOI: http://doi.org/10.3389/fcimb.2012.00022

PRACHANTASENA, S.; CHARUNUNTAKORN, P.; MUANGNOICHAROEN, S.; HANKLA, L.; TECHAWAL, $N$. et al. Distribution and genetic profiles of Campylobacter in commercial broiler production from breeder to slaughter in Thailand. PLoS One, v. 11, n. 2, p. 1-16, 2016. DOI: https://doi.org/10.1371/journal.pone.0149585

RAJAN, R.; ZHU, J.; HU, X.; PEI, D.; BELL, C. E. Crystal structure of Sribosylhomocysteinase (LuXS) in complex with a catalytic 2-ketone intermediate. Biochemistry, v. $44, \quad$ n. $10, \quad$ p. $3745-3753,2005 . \quad$ DOI: https://doi.org/10.1021/bi0477384

REESER, R. J. MEDLER, R. T.; BILLINGTON, S. J.; JOST, B. H.; JOENS, L. A. Characterization of Campylobacter jejuni biofilms under defined growth conditions. Applied and Environmental Microbiology, v. 73, n. 6, p. 1908 1913, 2007. DOI: https://doi.org/10.1128/AEM.00740-06

REUTER, M.; MALLETT, A.; PEARSON, B. M.; VAN VLIET, A. H. Biofilm formation by Campylobacter jejuni is increased under aerobic conditions. Applied and Environmental Microbiology, v. $76, \quad$ p. 2122-2128, 2010. DOI: http://doi.org/10.1128/AEM.01878-09

REVEZ, J.; ROSSI, M.; ELLSTRÖM, P.; DE HAAN, C.; RAUTELIN, H. et al. Finnish Campylobacter jejuni strains of multilocus sequence type ST-22 complex have two lineages with different characteristics. PLoS One, v. 6, p. 4-11, 2011. DOI: https://doi.org/10.1371/journal.pone.0026880 
ROILA, R.; VALIANI, A.; MIRAGLIA, D.; RANUCCI, D.; FORTE, C. et al. Olive mill wastewater phenolic concentrate as natural antioxidant against lipid-protein oxidative deterioration in chicken meat during storage. Italian Journal of Food Safety, v.7, n.3, p 148, 2018. DOI: http://dx.doi.org/10.4081/ijfs.2018.7342

ROILA, R.; RANUCCI, D.; VAIANI, A.; GALARINI, R.; SERVILI, M.; BRANCIARI, R. Antimicrobial and anti-biofilm activity of olive oil by-products against Campylobacter spp. isolated from chicken meat. Acta Scientiarum Polonorum, v. 18, n.1, p. 43-52, 2019. DOI: http://dx.doi.org/10.17306/J.AFS.2019.0629

ROSSI, D. A.; MENDONÇA, E. P.; MONTEIRO, G. P. Biofilms of Salmonella and Campylobacter in the poultry industry. In: MANAFI, M. Poultry Science, IntechOpen, 2016. DOI: http://doi.org/10.5772/61986

ROWE, M. T.; MADDEN, R. H.Campylobacter introduction. In: BATT, C. A.;TORTORELLO, M. L. (Ed.), Encyclopedia of food microbiology.2 ed. Oxford: Academic Press, 2014, p. 351-356.

SIMÕES, M. SIMÕES, L. C.; MACHADO, I.; PEREIRA, M. O.; VIEIRA, M. J. Control of flow-generated biofilms using surfactants - Evidence of resistance and recovery. Food and Bioproducts Processing, v. 84. n. 4, p. 338345, 2006. DOl: https://doi.org/10.1205/fbp06022

SIRINGAN, P.; CONNERTON, P. L.; PAYNE, R. J.; AND CONNERTON, I. F. Bacteriophage-mediated dispersal of Campylobacter jejuni biofilms. Applied and Environmental Microbiology, v. 77, p. 3320-3326, 2011. DOl: http://doi.org/10.1128/AEM.02704-10

SIVADON-TARDY, V. PORCHER, R.; ORLIKOWSKI, D.; RONCO, E.; GAULT, E. et al. Increased incidence of Campylobacter jejuni associated Guillain-Barre syndromes in the Greater Paris area. Epidemiology and Infection, v. 142, n. 8, p. 1609-1613, 2014. DOI: https://doi.org/10.1017/S095026881300263X

SKARP, C. P. A.; HÄNNINEN, M. L.; RAUTELIN, H. I. K. Campylobacteriosis: the role of poultry meat. Clinical microbiology and infection, v. 22, p. 103-109, 2016. DOI: https://doi.org/10.1016/j.cmi.2015.11.019

SREY, S.; JAHID, I. K.; HA, S. D. Biofilm formation in food industries: A food safety concern. Food Control, v. 31, n. 2, p. 572-585, 2013. DOl: https://doi.org/10.1016/j.foodcont.2012.12.001

STETSENKO, V. V.; EFIMOCHKINA, N. R.; PICHUGINA, T. V. Growth and Persistence of Campylobacter jejuni in Foodstuffs. Bulletin of Experimental Biology and Medicine, v. 166, n. 6, p. 759-765, 2019. DOI http://doi.org/10.1007/s10517-019-04435-x

STINTZI, A.; WHITWORTH, L. Investigation of the Campylobacter jejuni cold-shock response by global transcript. Genome Letters, v. 2, n. 1-2, p. 18-27, 2003. DOI: https://doi.org/10.1166/gl.2003.000 
SUNG, K.; KHAN, S. Biofilm development by Campylobacter jejuni. In: POMETTO, A. L.; DEMIRCI, A. (Ed.). Biofilms in the Food Environment, 2 ed. John Wiley \& Sons, 2015. p. 29-50.

SVENSSON S., L.; PRYJMA, M.; GAYNOR, E. C. Flagella-mediated adhesion and extracellular DNA release contribute to biofilm formation and stress tolerance of Campylobacter jejuni. PLoS ONE, v. 9, n. 8, 2014. DOI: http://doi.org/10.1371/journal.pone.0106063

TAKAHASHI, M. KROGA, M.; YOKOYAMA, K.; YUKI, N. Epidemiology of Campylobacter jejuni isolated from patients with Guillain-Barre and Fisher syndromes in Japan. Journal of Clinical Microbiology, v.43, p.335-339, 2005. DOI: https://doi.org/10.1128/JCM.43.1.335-339.2005

TECHARUVICHIT, P.; TAKAHASHI, H.; KUDA, T.; MIYA, S.; KEERATIPIBUL, S. et al. Adaptation of Campylobacter jejuni to biocides used in the food industry affects biofilm structure, adhesion strength, and cross-resistance to clinical antimicrobial

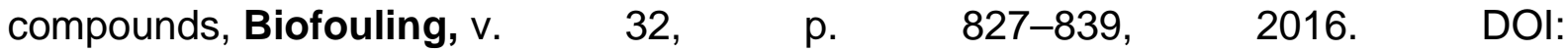
http://doi.org/10.1080/08927014.2016.1198476

TEH, A. H. T.; LEE, S. M.; DYKES, G. A. Association of some Campylobacter jejuni with Pseudomonas aeruginosa biofilms increases attachment under conditions mimicking those in the environment. Plos One, 2019a. DOI: https://doi.org/10.1371/journal.pone.0215275

TEH, A. H. T.; LEE, S. M.; DYKES, G. A. Growth in the presence of specific antibiotics induces biofilm formation by a Campylobacter jejuni strain sensitive to them but not in resistant strains. Journal of Global Antimicrobial Resistance, v. 18, p. 55-58, 2019b. DOI: https://doi.org/10.1016/j.jgar.2019.05.020

TURONOVA, H.; BRIANDET, R.; RODRIGUES, R.; HERNOULD, M.; HAYEK. et al. 2015. Biofilm spatial organization by the emerging pathogen Campylobacter jejuni: comparison between NCTC 11168 and 81-176 strains under microaerobic and oxygen-enriched conditions. Frontiers in Microbiology, v. 6, p. 1-11, 2016. DOI: https://doi.org/10.3389/fmicb.2015.00709

VESTERLUND, S.; PALTTA, J.; OUWEHAND, A. C. Measurement of bacterial adhesion in vitro evaluation of different methods. Journal of Microbiological Methods, v. 60, n. 2, p. 225-233, 2005. DOI: https://doi.org/10.1016/j.mimet.2004.09.013

WAGLE, B. R.; UPADHYAY, A.; UPADHYAY, I.; SHRESTHA, S.; ARSI, K. et al. Trans-Cinnamaldehyde, Eugenol and Carvacrol Reduce Campylobacter jejuni Biofilms and Modulate Expression of Select Genes and Proteins. Frontiers in Microbiology, v. 10, 2019. DOI: https://doi.org/10.3389/fmicb.2019.01837

WHO (World Health Organization). Campylobacter. 2017. Disponível em: http://www.who.int/mediacentre/factsheets/fs255/en/. Acesso em: 01/05/2019. 